\title{
How to set up a dynamic residual flow regime: the example of the River Spöl (Swiss National Park)
}

\section{Thomas Scheurer}

Keywords: hydropower, artificial floods, Spöl

\section{Abstract}

Profile

Since the year 2000 the artificial floods on the River Spöl have been considered a model of an ecologically optimized residual flow regime. It had not been possible to carry out the necessary transformation of residual flow within the permits effective at the time. The Federal Energy Office and the Governing Council of Grisons canton had to issue non-permanent exceptions. Recently these were replaced by a definitive regulation, which makes periodic floods a regular feature in the flow regime of the River Spöl.
Protected area

Swiss National Park

Mountain range

Alps

Country

\section{Switzerland}

\section{Residual water degrades the ecological in - tegrity of rivers}

The hydropower of the River Spöl - the largest running water in the Swiss National Park (SNP) - has been harnessed for electricity production since 1970 . To this end, the River Spöl (Figure 1) has been dammed directly outside the SNP in the Livigno reservoir and in the compensating reservoir Ova Spin (Figure 2). The residual water measured $1 \mathrm{~m}^{3} / \mathrm{s}$ in annual average and within just 20 years led to a situation where the River Spöl turned into a shallow body of water in the ravine between the two dams, interspersed in many places with transverse obstructions to form still water areas where mud and algae collected.

\section{More dynamics through artificial floods}

In 1990 the research council of the SNP was able to demonstrate in a national project (Gerster \& Rey 1994) that the ecological conditions can be greatly improved by floods. Thereafter the research council, in cooperation with power station operator Engadiner Kraftwerke (EKW), developed a proposal for a new residual flow regime with annual floods (Scheurer \& Molinari 2003). It started in 2000 and within just a few years has shown very promising results (Jakob et al. 2003; Mannes et al. 2008; Mürle et al. 2003; Robinson et al. 2003; Robinson \& Uehlinger 2003; Robinson et al. 2004; Robinson \& Uehlinger 2008).

\section{Transformation of the residual flow regime}

Prior to the transformation of the residual flow regime, extended negotiations with the power station operator and the regulating authorities (Swiss federation and Gris canton) took place. The permit for the

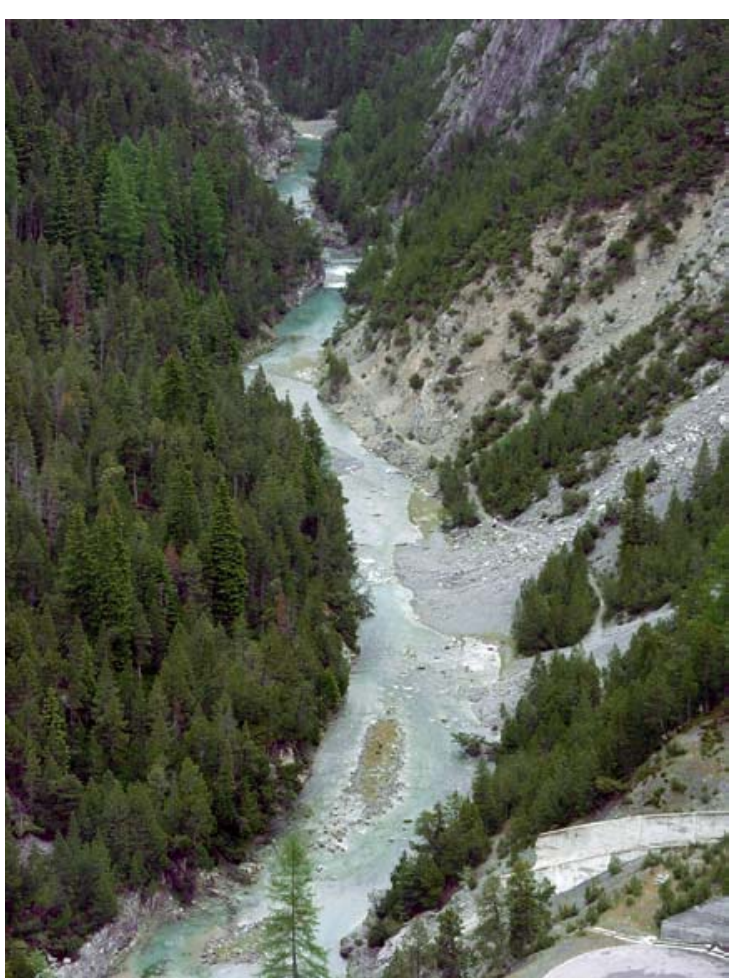

Figure 1 - View into the deep Spöl valley from the Punt dal Gall dam. Photograph by Hydra. (C) P. Rey

use of hydropower by the EKW between S-chanf and Martina regulates the water outtake down to the last litre, not least because it forms the basis on which water interest due to the canton and the municipalities is calculated. For the artificial floods to be implemented, the agreement of all affected parties was needed, which took about five years to obtain. From the year 2000, artificial floods were generated in the upper Spöl river, from the Punt dal Gall dam (Figure 3) and in the lower Spöl river from the Ova Spin compensation reservoir. 


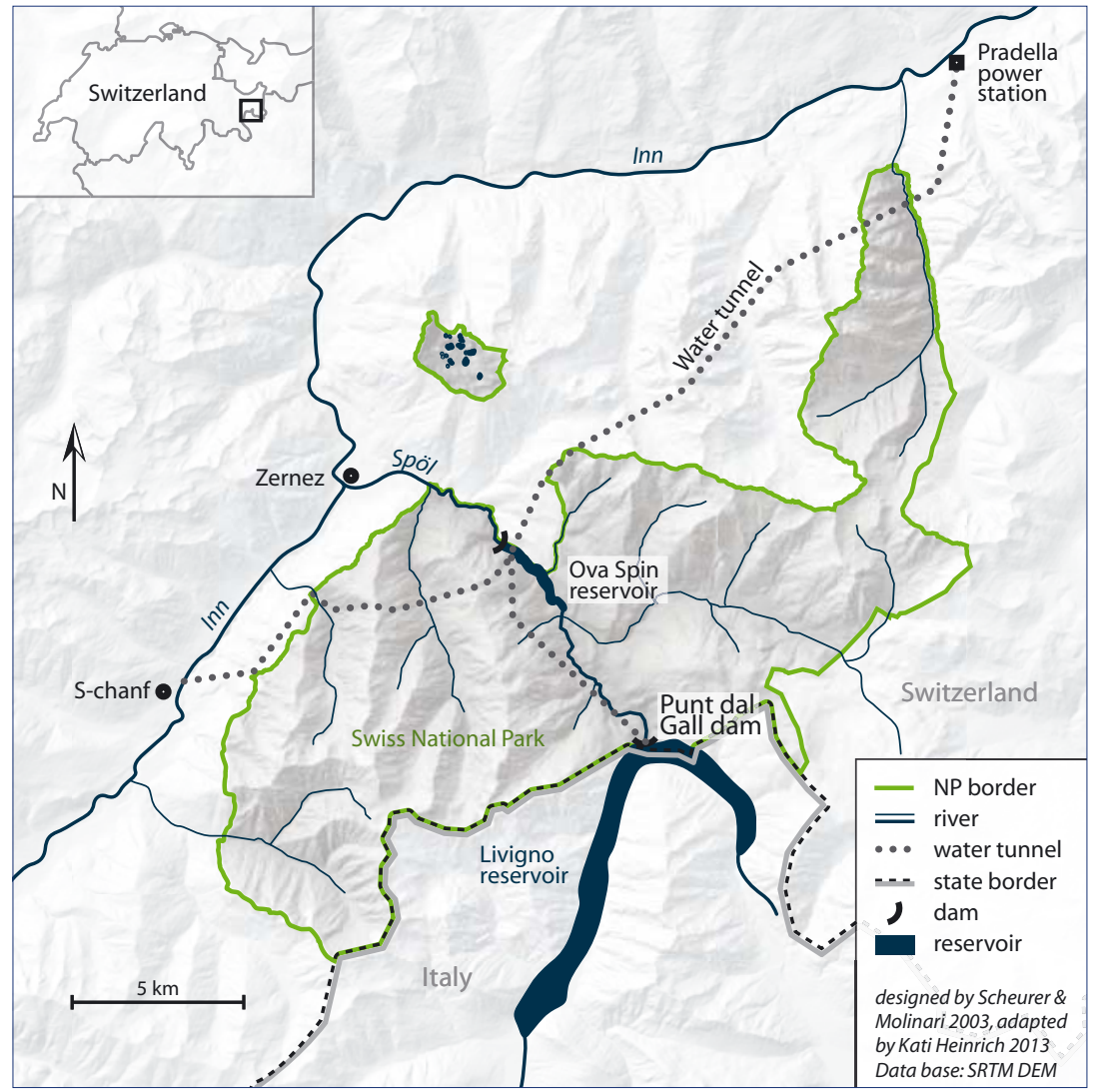

Figure 2-Map of the project area.

\section{New water balance}

The prerequisite for releasing artificial floods was the agreement of operator EKW. In order to actually carry out such artificial flooding, it was necessary to save up water in the reservoirs throughout the summer (15 May-15 September), which automatically meant decreasing the residual flow. This also meant that less electricity was produced because of the reduced amount of water for the residual flow turbines in the dams of Punt dal Gall and in Ova Spin. To compensate for this loss of production, some of the residual water kept in the Livigno dam and the Ova Spin reservoir was given over to the EKW for electricity production. By using this water via the next-higher power station level with bigger differential, the EKW were able to produce the same amount of electricity as before with less water. This production-neutral way of carrying out the floods was an essential prerequisite for obtaining the agreement of the EKW to the new residual flow regime.

\section{Impact on the permit}

Changing the distribution of the water outtake meant a deviation from the terms of the permit. This required the written consent of, first, the Federal Energy Office, responsible for the permit to use the upper Spöl, because it also involves using water from Italy for electricity production; second, the Governing Council of Grisons canton, which is responsible for the permit to use the lower Spöl; and, third, the affected municipalities. Consent to the new residual flow regime was given initially for a period of three years (2000-2002). Thereafter an extension had to be applied for.

\section{Remediation order}

Paragraph 80 of the Swiss Water Protection Act, amended in 2008, requires an ecological check and, if necessary, remediation of residual flow stretches. For the upper Spöl, the Federal Energy Office demanded such a check. The check brought to light that the flooding regime had considerably improved the ecological conditions in the River Spöl and must be continued. It also included proposals of further measures, which were, however, not in the interests of research (removal of the flow measuring station) or the SNP (removing tree seedlings from the river bed). In 2011 the Federal Energy Office issued a remediation order on the upper Spöl to make artificial floods a permanent feature. In this way, artificial floods could be legally integrated in the energy generation permit without the need to amend the permit itself. To date no similar order for the lower Spöl (Ova Spin - confluence with the River Inn) has been issued by the canton.

\section{More flexibility}

One important aim of the new residual flow regime backed by the remediation order is to achieve greater 
flexibility in the residual water outflow. In an agreement, signed in 2012 by EKW, SNP and Research Council, such flexibility was formally agreed. In future, both floods and basic outflow can be altered as needed by the ecological state of the river. Water that is not needed for flooding the Spöl can moreover be used sporadically in other running waters in the region that are affected by residual water or for larger rinses of Spöl and Inn. In this way the newly gained flexibility benefits other waters in the region as well. The agreement also includes a provision for monitoring the state of the water in the River Spöl (Robinson et al. 2011), a prerequisite for customized planning of the residual flow regime and the artificial floods.

\section{Mud flow event 2013}

For some thirteen years now, the dynamic residual water regime in the River Spöl has regularly mobilized fine sediment and rubble, renewed and improved habitats for water fauna. A running water trained by such stresses is also in a better position to cope with unusual events, such as the mudflow event at the end of March 2013, which was caused by unexpected sediment movements in the Livigno reservoir (Figure 4). Thanks to the regular mobilization of the fine sediment, there was relatively little fine sediment near the basic outflow and in the river. Based on several years of experience with artificial floods, experts were able to react in a targeted manner to the mud inflow. In this sense the dynamic residual flow management also minimizes the ecological risks in the case of technical accidents.

\section{A global perspective}

Since hydro-electric power stations must be regularly checked for functionality, rinses are carried out occasionally when the dams are emptied. Such technically required floods are however nowhere near enough for an ecological improvement of the waters affected by residual flow. What is needed to improve the ecological integrity are floods specifically designed for the benefit of the ecology of the waters in question, as these have been applied across the world forsome years (Konrad et al. 2011). Usually these are oneoff measures, sometimes spectacular ones, which are repeated as needed. Experiences with the floods in the Spöl have shown that for the water dynamics to be fundamentally improved, annual floods are needed. To date and as far as we know, the River Spöl is the only residual flow river with annual artificial flooding. It is hoped that the positive effects of the floods on the water ecology will encourage power station operators everywhere to change their residual flow management to a dynamic residual flow regime.

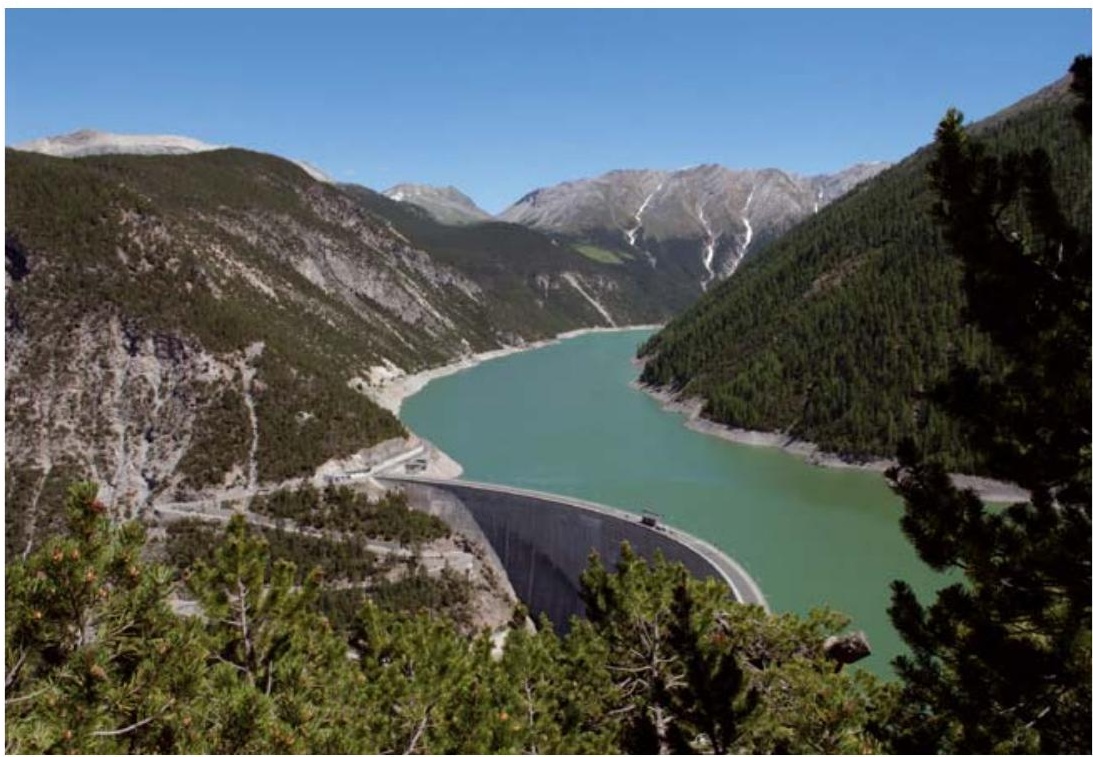

Figure 3 - Punt dal Gall dam and Livigno reservoir. The Punt dal gall dam is half in Switzerland and half in Italy. C SNP, H. Lozza

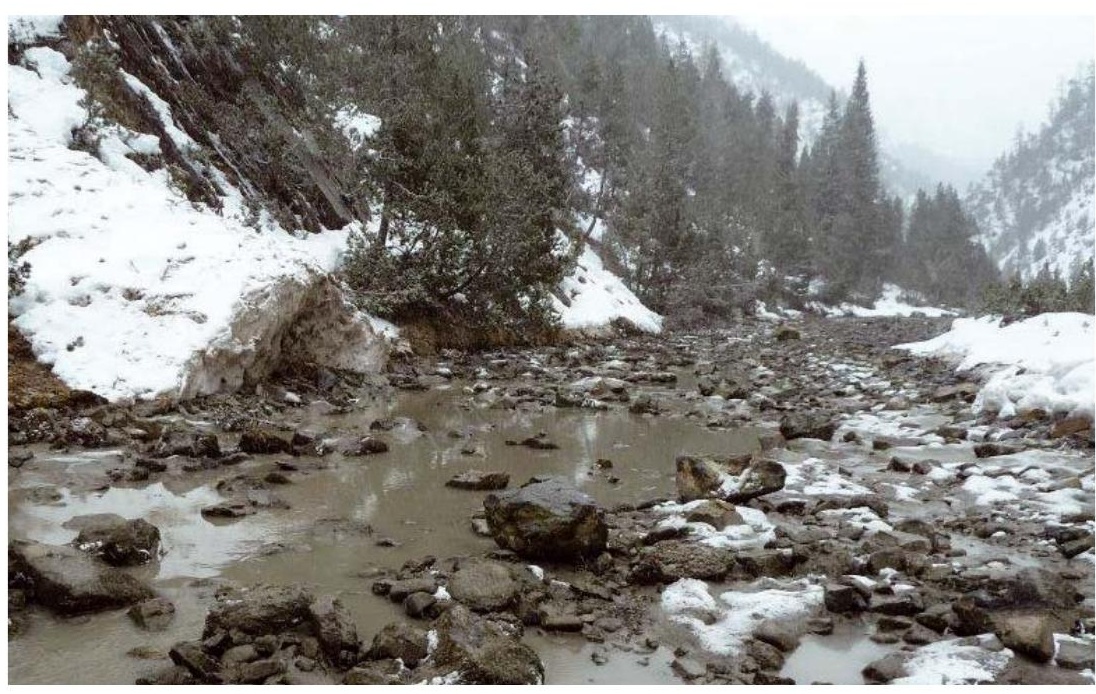

Figure 4 - River Spöl below the Punt dal Gall dam after a mudflow event at the end of March 2013 caused by unexpected sediment movements in the Livigno reservoir. (C) SNP, H. Lozza

\section{References}

Gerster, S. \& P. Rey 1994. Ökologische Folgen von Stauraumspülungen. Schriftenreibe Umweltschutz, 219. BUWAL, Bern, Switzerland.

Jakob, C., C.T. Robinson \& U. Uehlinger 2003. Longitudinal effects of experimental floods on stream benthos downstream from a large dam. Aquatic Sciences 65: 223-231.

Konrad C.P., J.D. Olden, D.A. Lytle, T. Melis, J.C. Schmidt, E. Bray, M. Freemann, K. Keith Gido, N. Hemphill, M. Kennard, L. McMullen, M.C. Mims, M. Pyron, C.T. Robinson, J.G. Williams 2011. Large-scale flow experiments for managing river systems. BioScience 61 (12): 948-959.

Mannes, S., C.T. Robinson, U. Uehlinger, T. Scheurer, J. Ortlepp, U. Mürle \& P. Molinari 2008. Ecological 
effects of a long-term flood program in a flow-regulated river. Journal of Alpine Research 96 (1): 113-134.

Mürle, U., J. Ortlepp \& M. Zahner 2003. Effects of experimental flooding on riverine morphology, structure an riparian vegetation: The River Spöl, Swiss National Park. Aquatic Sciences 65: 191-198.

Robinson, C.T. \& U. Uehlinger 2003. Using artificial floos for restoring river integrity. Aquatic Sciences 65: 181-182.

Robinson, C.T., U. Uehlinger, M.T. Monaghan 2003. Effects of multi-year experimental floods regime on macro-invertebrates downstream of a reservoir. Aquatic Sciences 65: 210-222.

Robinson, C.T., P. Molinari, U. Mürle, J. Ortlepp, T. Scheurer, U. Uehlinger \& M. Zahner 2004. Experimental floods to improve the integrity of regulated rivers. GALA 13 (3): 186-190.

Robinson, C.T. \& U. Uehlinger 2008. Experimental floods cause ecosystem regime shift in a regulated river. Ecological Applications 18 (2): 511-526.
Robinson, C.T., M. Doering \& L. Seelen 2011. Importance of protected areas for freshwater biomonitoring - Case studies in Switzerland. eco.mont 3 (2): 13-22.

Scheurer, T. \& P. Molinari 2003. Experimental floods in the River Spöl, Swiss National Park: Framework, objectives, design. Aquatic Sciences 65: 183-190.

\section{Author}

\section{Thomas Scheurer}

Dr. phil. nat, 1953. Studied Geography, Geology and Anthopology at the University of Berne. Currently managing director of the Swiss National Park Research Council, the Swiss Interacademic Commission for Alpine Studies, and the International Scientific Committee for Alpine Research. 